\title{
Maternidad/Paternidad: el declive de roles sociales con- vencionales en una muestra de universitarios(as)
}

\author{
Maternity / Paternity: the decline of conventional social roles in a sample of university students \\ Maternidade / Paternidade: o declínio dos papéis sociais convencionais em uma amostra de \\ estudiantes universitarios
}

Yenny Patricia Moreno-Rangel ${ }^{1}$

Edgar Alexander Rincón-Silva ${ }^{2}$

\begin{abstract}
Autor de correspondencia*
${ }^{1^{*}}$ Enfermera UIS, Mg. Mujeres y Salud UCM, Mg. Salud Sexual y Reproductiva Universidad El Bosque, Docente/Investigadora programa de enfermería Fundación Universitaria de San Gil- UNISANGIL Colombia Correo: ymoreno@unisangil. edu.co (iD)

${ }^{2}$ Hisoriador UIS, Estudiante Doctorado en Educación U Baja California, $\mathrm{Mg} \mathrm{Sa}$ lud Sexual y Reproductiva Universidad El Bosque, Docente /Investigador Programa de Enfermería Fundación Universidad de San Gil - UNISANGIL. Correo: erincon@ unisangil.edu.co (iD)
\end{abstract}

\section{Resumen}

Objetivo: Determinar las percepciones sobre la maternidad y paternidad de un grupo de estudiantes adolescentes y jóvenes universitarios en Santander (Colombia) en el 2019. Materiales y métodos: Estudio cualitativo descriptivo con enfoque desde la teoría fundamentada; se realizaron 22 entrevistas a jóvenes universitarios. La técnica de recolección de datos fue la entrevista semiestructurada con guión validado por expertos. El proyecto fue aprobado por el comité de ética de investigación de la Fundación Universitaria de San Gil UNISANGIL. Resultados: Gran parte de los entrevistados dan cuenta de su decisión de postergar e incluso descartar la idea de la maternidad/ paternidad de su proyecto de vida anteponiendo logros académicos y laborales; asumir el ser madre o padre durante la vida universitaria es un gran reto para los jóvenes y puede suponer un freno para aquellos que buscan mejorar su calidad de vida y superar ciclos de pobreza. Conclusiones: La investigación permitió dar cuenta de los cambios que se comienzan a gestar en las intenciones de los jóvenes de posponer o definitivamente no optar por la maternidad y /o la paternidad en sus aspiraciones vitales.

Palabras Clave: Roles de la mujer; roles del hombre; género y salud; sexualidad; anticoncepción; adolescente; adulto joven; servicios de Salud; estudiantes. 


\begin{abstract}
Objective: To determine the perceptions about motherhood and fatherhood of a group of adolescent students and young university students in Santander (Colombia) in 2019. Materials and methods: Descriptive qualitative study with a grounded theory approach; 22 interviews were conducted with young university students. The data collection technique was the semi-structured interview with a script validated by experts. The project was approved by the research ethics committee of the Foundation Universitaria de San Gil UNISANGIL. Results: A large part of the interviewees gave an account of their decision to postpone and even discard the idea of motherhood / fatherhood from their life project, putting academic and work achievements first; assume being a mother or father during life College is a great challenge for young people and can be a brake for those who seek to improve their quality of life and overcome cycles of poverty. Conclusions: The research allowed to give account of the changes that are beginning to take shape in the intentions of young people to postpone or definitely not choose motherhood and / or fatherhood in their life aspirations.
\end{abstract}

Key Words: Roles of women; roles of men; Social construction of gender; gender and health; sexuality; contraception; adolescent; young adult; Health Services; Students.

\title{
Resumo
}

Objetivo: Determinar as percepções sobre a maternidade e a paternidade de um grupo de dolescentes estudantes e jovens universitários de Santander (Colômbia) em 2019. Materiais e métodos: Estudo qualitativo descritivo com abordagem da teoria fundamentada; Foram realizadas 22 entrevistas com jovens universitários. A técnica de coleta de dados foi a entrevista semiestruturada com roteiro validado por especialistas. O projeto foi aprovado pelo comitê de ética em pesquisa da Fundación Universitaria de San Gil UNISANGIL. Resultados: Grande parte das entrevistadas relatou sua decisão de adiar e até mesmo descartar a ideia de maternidade / paternidade de seu projeto de vida, priorizando as conquistas acadêmicas e profissionais; assumir o ser pai ou mãe durante a vida. A faculdade é um grande desafio para os jovens e pode ser um freio para aqueles que buscam melhorar sua qualidade de vida e superar ciclos de pobreza. Conclusões: A pesquisa permitiu dar conta as mudanças que começam a se delinear nas intenções dos jovens de adiar ou definitivamente não optar pela maternidade e / ou paternidade em suas aspirações de vida.

Palavras-chave: Papéis das mulheres; papéis dos homens; gênero e saúde; sexualidade; contracepção; adolescente; adulto jovem; Serviços de saúde; Estudantes.

\section{Introducción}

El embarazo no planeado, representa un evento que trastorna los proyectos y planes de los jóvenes y adolescentes, debido a que por lo general deben asumir nuevas responsabilidades, pues se adquiere el rol de la maternidad o la paternidad, y en el caso de este grupo etario que tienen dentro de su proyecto de vida, la formación universitaria, contraer dichas responsabilidades puede sig- nificar el abandono de sus estudios (1-3).

Esta deserción universitaria es un hecho preocupante, pues la educación superior se reconoce como un elemento importante en la construcción del capital humano de un país; permite al estudiante la adquisición de destrezas y habilidades profesionales para forjarse una mejor calidad de vida, y es por esto que aumentar el ingreso a la educación superior y disminuir la deserción de los jóvenes universitarios es uno de los retos de 
las políticas educativas en América Latina, debido a que se considera que la movilidad social asociada a la formación del capital humano está mediada por la culminación de los estudios superiores, dado que permite obtener mejores empleos y mayores ingresos salariales, facilitando acceder a una mejor calidad de vida.

De esta forma, el bajo porcentaje de ingreso a la universidad sumado a la posterior deserción universitaria, son obstáculos que impiden que los jóvenes alcancen sus metas de bienestar y calidad de vida $(4,5)$.

La minimización de la deserción resulta crucial en un país como Colombia, que aunque ha alcanzado un acceso casi universal a educación básica primaria, el ingreso a la educación superior no supera el $10 \%$ de los egresados de la educación media $(6,7) 2009$.

Por otra parte, el análisis de esta situación desde una perspectiva de género permite entrever la asignación de responsabilidad ante un embarazo e interrupción de estudios mayoritariamente sobre la mujer, quien debe superar el reto de la continuidad de los estudios, dada la dificultad que supone conciliar la gestación, el parto y la crianza con la vida académica (8-10), así mismo, estos roles pesan mucho a la hora de tomar decisiones frente a la reincorporación a la fuerza laboral de muchas mujeres, elementos que contribuyen a reforzar las brechas de género $(11,12)$.

Sumado a lo anterior, la Encuesta Nacional de Demografía y Salud (ENDS) 2015 (13)notably different from any of its congeners. Several specimens of the undescribed species subsequently were located in several museums; because the new species closely resembles M. gilvicollis (Lined Forest-Falcon, indicó que los embarazos a muy temprana edad forman parte del patrón cultural de algunas regiones y grupos sociales, pero generalmente no son deseados y se dan en parejas que no han iniciado una vida en común, configurando así el problema social de la "madre soltera".

Por lo tanto, el análisis e intervención de la fecundidad adolescente resulta una herramienta valiosa para los implicados en el bienestar universitario pues los déficit en salud sexual y reproductiva de las y los adolescentes y jóvenes tienen consecuencias sociales, económicas y de salud $(14,15)$.

Lo anteriormente planteado, da pautas para interrogarse sobre las percepciones de los jóvenes y adolescentes frente a la maternidad y paternidad; cuál es el lugar que ocupan en su plan de vida, y cómo afecta la posibilidad de alcanzar los objetivos psicosociales propios de la adolescencia tardía (18-21 años), los cuales son necesarios en la evolución del joven a la edad adulta, como son: lograr la independencia, aceptar su imagen corporal, establecer relaciones con los amigos y lograr su identidad, coincidiendo con la culminación de la educación superior(16).

\section{Objetivos}

\section{Objetivo General}

Determinar las percepciones sobre la maternidad y paternidad dentro de su proyecto de vida en un grupo de estudiantes universitarios de un municipio de Santander.

\section{Objetivos específicos}

- Caracterizar socio demográficamente a los estudiantes participantes del estudio.

- Describir la percepción que se tiene de la inclusión de la Maternidad/Paternidad en el proyecto de Vida.

\section{Materiales y Métodos}

Se realizó un estudio cualitativo de corte interpretativo. Se eligió este tipo de estudio porque se busca trascender al sujeto social para explicar y comprender hechos o fenómenos sociales más complejos (17). Como herramienta de recolección de datos se utilizó la entrevista semiestructurada cuyo guión fue validado previamente por expertos (18).

Para la construcción del guion de la entrevista se realizó una revisión de literatura que permitió identificar algunos ítems de las categorías a estudio, complementados con datos sociodemográficos y uso y preferencia de anticonceptivos. Las categorías a estudio se definieron como:

Sentido del Rol Materno/Paterno. Creencias, actitudes, opiniones, estereotipos y conocimientos acerca del rol materno, entendiendo el rol como la conducta asociada con la posición particular de madre (y padre) en el sistema social; de 
manera que dicha conducta satisfaga las expectativas que los otros albergan con respecto al comportamiento esperado para su posición de madre/ padre (19-20).

Inclusión de la Maternidad/Paternidad en el Proyecto de Vida. Creencias, actitudes, opiniones, estereotipos y conocimientos acerca de la forma como la mujer y el hombre consideran posible, probable u oportuno concebir un hijo(a) y la incidencia de su condición de madre/padre en su futuro y desarrollo personal y social (21).

La población objeto de estudio se constituyó por estudiantes universitarios de pregrado, quienes fueron invitados a hacer parte de la investigación de forma voluntaria. Finalmente se contó con la participación de 22 estudiantes, constituyéndose una muestra a conveniencia no aleatorizada, basada en la disponibilidad de los y las estudiantes a ser entrevistados. Se aplicaron los criterios de inclusión: aceptar voluntariamente la participación, ser mayores de 14 años, no tener hijos y estar cursando una carrera de pregrado en la Fundación Universitaria de San Gil. El estado civil y estar en una relación estable o no, no fue tenido en cuenta como criterio de inclusión.

Las entrevistas fueron únicas y se efectuaron por parte de los investigadores en el periodo comprendido entre mayo y agosto del 2019, con una duración promedio de 35 minutos. Se realizaron en aulas cerradas y privadas de la universidad, previa lectura y firma del consentimiento informado avalado por la institución. Fueron audio grabadas y transcritas en su totalidad por los investigadores, bajo códigos que garantizaban el anonimato de las personas participantes.

Para la interpretación, análisis y posterior identificación de las categorías emergentes de las entrevistas, los dos investigadores realizaron en conjunto el proceso inductivo de agrupamiento de los datos elaborando categorías, generando aportaciones conceptuales y ratificando hallazgos. Para apoyar este proceso se utilizó el software Atlas.ti 8 que permitió la diagramación de las relaciones y crear conjuntos de datos facilitando la interpretación de los mismos.

Respecto a los criterios éticos, el presente estudio se enmarca-en los lineamientos de la Resolución 8430 de 1993, en la cual se establecen las normas científicas, técnicas y administrativas para la investigación en salud(24). En cuanto al consentimiento de menores de edad se acogió la Sentencia C-131/14 de la Corte Constitucional, que permite a los mayores de 14 años ser considerados "menores adultos o púberes", a los cuales legalmente se les respeta su libertad de autodeterminación. El proyecto fue aprobado por el Comité de Ética de Investigación de la Fundación Universitaria de San Gil- UNISANGIL.

\section{Resultados}

\section{La primera parte de los resultados corresponde a
la caracterización por edad y sexo de los partici-
pantes en la investigación. Fueron entrevistados
un total de 22 estudiantes de una universidad pri-
vada, matriculados para el segundo semestre del
año 2019 en las carreras de Licenciatura en Peda-
gogía Infantil, Enfermería, Derecho, Psicología
e Ingeniería Eléctrica. Ocho de los entrevistados
fueron hombres (36\%) y 14 mujeres (64\%), con
edades entre los 17 y 28 años, siendo la edad más
frecuente los 19 años cumplidos.
Se describió también el inicio de relaciones se-
xuales y uso de anticonceptivos de los y las par-
ticipantes; de los 22 entrevistados, 17 afirmaron
haber iniciado su vida sexual (cifra que corres-
ponde al $77 \%$ de los participantes) y 15 de ellos
reportaron el uso de anticonceptivos. De las 14
mujeres participantes, diez afirmaron haber co-
menzado relaciones sexuales, , mientras que de
los ocho hombres participantes, siete afirmaron
tener relaciones sexuales.
Los anticonceptivos más usados por la población
entrevistada son el condón y métodos orales. El
primero es preferido por los varones y el segun-
do por las mujeres. Las razones argumentadas
para la elección del anticonceptivo son variadas:
desde la seguridad que ofrece el método para no
tener hijos, la recomendación médica, la facili-
dad de conseguirlos y usarlos hasta el control que
brindan y su popularidad.
Percepciones emergentes \\ La primera parte de los resultados corresponde a
la caracterización por edad y sexo de los partici-
pantes en la investigación. Fueron entrevistados
un total de 22 estudiantes de una universidad pri-
vada, matriculados para el segundo semestre del
año 2019 en las carreras de Licenciatura en Peda-
gogía Infantil, Enfermería, Derecho, Psicología
e Ingeniería Eléctrica. Ocho de los entrevistados
fueron hombres (36\%) y 14 mujeres (64\%), con
edades entre los 17 y 28 años, siendo la edad más
frecuente los 19 años cumplidos.
Se describió también el inicio de relaciones se-
xuales y uso de anticonceptivos de los y las par-
ticipantes; de los 22 entrevistados, 17 afirmaron
haber iniciado su vida sexual (cifra que corres-
ponde al $77 \%$ de los participantes) y 15 de ellos
reportaron el uso de anticonceptivos. De las 14
mujeres participantes, diez afirmaron haber co-
menzado relaciones sexuales, , mientras que de
los ocho hombres participantes, siete afirmaron
tener relaciones sexuales.
Los anticonceptivos más usados por la población
entrevistada son el condón y métodos orales. El
primero es preferido por los varones y el segun-
do por las mujeres. Las razones argumentadas
para la elección del anticonceptivo son variadas:
desde la seguridad que ofrece el método para no
tener hijos, la recomendación médica, la facili-
dad de conseguirlos y usarlos hasta el control que
brindan y su popularidad.
Percepciones emergentes \\ La primera parte de los resultados corresponde a
la caracterización por edad y sexo de los partici-
pantes en la investigación. Fueron entrevistados
un total de 22 estudiantes de una universidad pri-
vada, matriculados para el segundo semestre del
año 2019 en las carreras de Licenciatura en Peda-
gogía Infantil, Enfermería, Derecho, Psicología
e Ingeniería Eléctrica. Ocho de los entrevistados
fueron hombres (36\%) y 14 mujeres (64\%), con
edades entre los 17 y 28 años, siendo la edad más
frecuente los 19 años cumplidos.
Se describió también el inicio de relaciones se-
xuales y uso de anticonceptivos de los y las par-
ticipantes; de los 22 entrevistados, 17 afirmaron
haber iniciado su vida sexual (cifra que corres-
ponde al $77 \%$ de los participantes) y 15 de ellos
reportaron el uso de anticonceptivos. De las 14
mujeres participantes, diez afirmaron haber co-
menzado relaciones sexuales, , mientras que de
los ocho hombres participantes, siete afirmaron
tener relaciones sexuales.
Los anticonceptivos más usados por la población
entrevistada son el condón y métodos orales. El
primero es preferido por los varones y el segun-
do por las mujeres. Las razones argumentadas
para la elección del anticonceptivo son variadas:
desde la seguridad que ofrece el método para no
tener hijos, la recomendación médica, la facili-
dad de conseguirlos y usarlos hasta el control que
brindan y su popularidad.
Percepciones emergentes \\ La primera parte de los resultados corresponde a
la caracterización por edad y sexo de los partici-
pantes en la investigación. Fueron entrevistados
un total de 22 estudiantes de una universidad pri-
vada, matriculados para el segundo semestre del
año 2019 en las carreras de Licenciatura en Peda-
gogía Infantil, Enfermería, Derecho, Psicología
e Ingeniería Eléctrica. Ocho de los entrevistados
fueron hombres (36\%) y 14 mujeres (64\%), con
edades entre los 17 y 28 años, siendo la edad más
frecuente los 19 años cumplidos.
Se describió también el inicio de relaciones se-
xuales y uso de anticonceptivos de los y las par-
ticipantes; de los 22 entrevistados, 17 afirmaron
haber iniciado su vida sexual (cifra que corres-
ponde al $77 \%$ de los participantes) y 15 de ellos
reportaron el uso de anticonceptivos. De las 14
mujeres participantes, diez afirmaron haber co-
menzado relaciones sexuales, , mientras que de
los ocho hombres participantes, siete afirmaron
tener relaciones sexuales.
Los anticonceptivos más usados por la población
entrevistada son el condón y métodos orales. El
primero es preferido por los varones y el segun-
do por las mujeres. Las razones argumentadas
para la elección del anticonceptivo son variadas:
desde la seguridad que ofrece el método para no
tener hijos, la recomendación médica, la facili-
dad de conseguirlos y usarlos hasta el control que
brindan y su popularidad.
Percepciones emergentes \\ La primera parte de los resultados corresponde a
la caracterización por edad y sexo de los partici-
pantes en la investigación. Fueron entrevistados
un total de 22 estudiantes de una universidad pri-
vada, matriculados para el segundo semestre del
año 2019 en las carreras de Licenciatura en Peda-
gogía Infantil, Enfermería, Derecho, Psicología
e Ingeniería Eléctrica. Ocho de los entrevistados
fueron hombres (36\%) y 14 mujeres (64\%), con
edades entre los 17 y 28 años, siendo la edad más
frecuente los 19 años cumplidos.
Se describió también el inicio de relaciones se-
xuales y uso de anticonceptivos de los y las par-
ticipantes; de los 22 entrevistados, 17 afirmaron
haber iniciado su vida sexual (cifra que corres-
ponde al $77 \%$ de los participantes) y 15 de ellos
reportaron el uso de anticonceptivos. De las 14
mujeres participantes, diez afirmaron haber co-
menzado relaciones sexuales, , mientras que de
los ocho hombres participantes, siete afirmaron
tener relaciones sexuales.
Los anticonceptivos más usados por la población
entrevistada son el condón y métodos orales. El
primero es preferido por los varones y el segun-
do por las mujeres. Las razones argumentadas
para la elección del anticonceptivo son variadas:
desde la seguridad que ofrece el método para no
tener hijos, la recomendación médica, la facili-
dad de conseguirlos y usarlos hasta el control que
brindan y su popularidad.
Percepciones emergentes \\ La primera parte de los resultados corresponde a
la caracterización por edad y sexo de los partici-
pantes en la investigación. Fueron entrevistados
un total de 22 estudiantes de una universidad pri-
vada, matriculados para el segundo semestre del
año 2019 en las carreras de Licenciatura en Peda-
gogía Infantil, Enfermería, Derecho, Psicología
e Ingeniería Eléctrica. Ocho de los entrevistados
fueron hombres (36\%) y 14 mujeres (64\%), con
edades entre los 17 y 28 años, siendo la edad más
frecuente los 19 años cumplidos.
Se describió también el inicio de relaciones se-
xuales y uso de anticonceptivos de los y las par-
ticipantes; de los 22 entrevistados, 17 afirmaron
haber iniciado su vida sexual (cifra que corres-
ponde al $77 \%$ de los participantes) y 15 de ellos
reportaron el uso de anticonceptivos. De las 14
mujeres participantes, diez afirmaron haber co-
menzado relaciones sexuales, , mientras que de
los ocho hombres participantes, siete afirmaron
tener relaciones sexuales.
Los anticonceptivos más usados por la población
entrevistada son el condón y métodos orales. El
primero es preferido por los varones y el segun-
do por las mujeres. Las razones argumentadas
para la elección del anticonceptivo son variadas:
desde la seguridad que ofrece el método para no
tener hijos, la recomendación médica, la facili-
dad de conseguirlos y usarlos hasta el control que
brindan y su popularidad.
Percepciones emergentes \\ La primera parte de los resultados corresponde a
la caracterización por edad y sexo de los partici-
pantes en la investigación. Fueron entrevistados
un total de 22 estudiantes de una universidad pri-
vada, matriculados para el segundo semestre del
año 2019 en las carreras de Licenciatura en Peda-
gogía Infantil, Enfermería, Derecho, Psicología
e Ingeniería Eléctrica. Ocho de los entrevistados
fueron hombres (36\%) y 14 mujeres (64\%), con
edades entre los 17 y 28 años, siendo la edad más
frecuente los 19 años cumplidos.
Se describió también el inicio de relaciones se-
xuales y uso de anticonceptivos de los y las par-
ticipantes; de los 22 entrevistados, 17 afirmaron
haber iniciado su vida sexual (cifra que corres-
ponde al $77 \%$ de los participantes) y 15 de ellos
reportaron el uso de anticonceptivos. De las 14
mujeres participantes, diez afirmaron haber co-
menzado relaciones sexuales, , mientras que de
los ocho hombres participantes, siete afirmaron
tener relaciones sexuales.
Los anticonceptivos más usados por la población
entrevistada son el condón y métodos orales. El
primero es preferido por los varones y el segun-
do por las mujeres. Las razones argumentadas
para la elección del anticonceptivo son variadas:
desde la seguridad que ofrece el método para no
tener hijos, la recomendación médica, la facili-
dad de conseguirlos y usarlos hasta el control que
brindan y su popularidad.
Percepciones emergentes \\ La primera parte de los resultados corresponde a
la caracterización por edad y sexo de los partici-
pantes en la investigación. Fueron entrevistados
un total de 22 estudiantes de una universidad pri-
vada, matriculados para el segundo semestre del
año 2019 en las carreras de Licenciatura en Peda-
gogía Infantil, Enfermería, Derecho, Psicología
e Ingeniería Eléctrica. Ocho de los entrevistados
fueron hombres (36\%) y 14 mujeres (64\%), con
edades entre los 17 y 28 años, siendo la edad más
frecuente los 19 años cumplidos.
Se describió también el inicio de relaciones se-
xuales y uso de anticonceptivos de los y las par-
ticipantes; de los 22 entrevistados, 17 afirmaron
haber iniciado su vida sexual (cifra que corres-
ponde al $77 \%$ de los participantes) y 15 de ellos
reportaron el uso de anticonceptivos. De las 14
mujeres participantes, diez afirmaron haber co-
menzado relaciones sexuales, , mientras que de
los ocho hombres participantes, siete afirmaron
tener relaciones sexuales.
Los anticonceptivos más usados por la población
entrevistada son el condón y métodos orales. El
primero es preferido por los varones y el segun-
do por las mujeres. Las razones argumentadas
para la elección del anticonceptivo son variadas:
desde la seguridad que ofrece el método para no
tener hijos, la recomendación médica, la facili-
dad de conseguirlos y usarlos hasta el control que
brindan y su popularidad.
Percepciones emergentes \\ La primera parte de los resultados corresponde a
la caracterización por edad y sexo de los partici-
pantes en la investigación. Fueron entrevistados
un total de 22 estudiantes de una universidad pri-
vada, matriculados para el segundo semestre del
año 2019 en las carreras de Licenciatura en Peda-
gogía Infantil, Enfermería, Derecho, Psicología
e Ingeniería Eléctrica. Ocho de los entrevistados
fueron hombres (36\%) y 14 mujeres (64\%), con
edades entre los 17 y 28 años, siendo la edad más
frecuente los 19 años cumplidos.
Se describió también el inicio de relaciones se-
xuales y uso de anticonceptivos de los y las par-
ticipantes; de los 22 entrevistados, 17 afirmaron
haber iniciado su vida sexual (cifra que corres-
ponde al $77 \%$ de los participantes) y 15 de ellos
reportaron el uso de anticonceptivos. De las 14
mujeres participantes, diez afirmaron haber co-
menzado relaciones sexuales, , mientras que de
los ocho hombres participantes, siete afirmaron
tener relaciones sexuales.
Los anticonceptivos más usados por la población
entrevistada son el condón y métodos orales. El
primero es preferido por los varones y el segun-
do por las mujeres. Las razones argumentadas
para la elección del anticonceptivo son variadas:
desde la seguridad que ofrece el método para no
tener hijos, la recomendación médica, la facili-
dad de conseguirlos y usarlos hasta el control que
brindan y su popularidad.
Percepciones emergentes \\ La primera parte de los resultados corresponde a
la caracterización por edad y sexo de los partici-
pantes en la investigación. Fueron entrevistados
un total de 22 estudiantes de una universidad pri-
vada, matriculados para el segundo semestre del
año 2019 en las carreras de Licenciatura en Peda-
gogía Infantil, Enfermería, Derecho, Psicología
e Ingeniería Eléctrica. Ocho de los entrevistados
fueron hombres (36\%) y 14 mujeres (64\%), con
edades entre los 17 y 28 años, siendo la edad más
frecuente los 19 años cumplidos.
Se describió también el inicio de relaciones se-
xuales y uso de anticonceptivos de los y las par-
ticipantes; de los 22 entrevistados, 17 afirmaron
haber iniciado su vida sexual (cifra que corres-
ponde al $77 \%$ de los participantes) y 15 de ellos
reportaron el uso de anticonceptivos. De las 14
mujeres participantes, diez afirmaron haber co-
menzado relaciones sexuales, , mientras que de
los ocho hombres participantes, siete afirmaron
tener relaciones sexuales.
Los anticonceptivos más usados por la población
entrevistada son el condón y métodos orales. El
primero es preferido por los varones y el segun-
do por las mujeres. Las razones argumentadas
para la elección del anticonceptivo son variadas:
desde la seguridad que ofrece el método para no
tener hijos, la recomendación médica, la facili-
dad de conseguirlos y usarlos hasta el control que
brindan y su popularidad.
Percepciones emergentes \\ La primera parte de los resultados corresponde a
la caracterización por edad y sexo de los partici-
pantes en la investigación. Fueron entrevistados
un total de 22 estudiantes de una universidad pri-
vada, matriculados para el segundo semestre del
año 2019 en las carreras de Licenciatura en Peda-
gogía Infantil, Enfermería, Derecho, Psicología
e Ingeniería Eléctrica. Ocho de los entrevistados
fueron hombres (36\%) y 14 mujeres (64\%), con
edades entre los 17 y 28 años, siendo la edad más
frecuente los 19 años cumplidos.
Se describió también el inicio de relaciones se-
xuales y uso de anticonceptivos de los y las par-
ticipantes; de los 22 entrevistados, 17 afirmaron
haber iniciado su vida sexual (cifra que corres-
ponde al $77 \%$ de los participantes) y 15 de ellos
reportaron el uso de anticonceptivos. De las 14
mujeres participantes, diez afirmaron haber co-
menzado relaciones sexuales, , mientras que de
los ocho hombres participantes, siete afirmaron
tener relaciones sexuales.
Los anticonceptivos más usados por la población
entrevistada son el condón y métodos orales. El
primero es preferido por los varones y el segun-
do por las mujeres. Las razones argumentadas
para la elección del anticonceptivo son variadas:
desde la seguridad que ofrece el método para no
tener hijos, la recomendación médica, la facili-
dad de conseguirlos y usarlos hasta el control que
brindan y su popularidad.
Percepciones emergentes \\ La primera parte de los resultados corresponde a
la caracterización por edad y sexo de los partici-
pantes en la investigación. Fueron entrevistados
un total de 22 estudiantes de una universidad pri-
vada, matriculados para el segundo semestre del
año 2019 en las carreras de Licenciatura en Peda-
gogía Infantil, Enfermería, Derecho, Psicología
e Ingeniería Eléctrica. Ocho de los entrevistados
fueron hombres (36\%) y 14 mujeres (64\%), con
edades entre los 17 y 28 años, siendo la edad más
frecuente los 19 años cumplidos.
Se describió también el inicio de relaciones se-
xuales y uso de anticonceptivos de los y las par-
ticipantes; de los 22 entrevistados, 17 afirmaron
haber iniciado su vida sexual (cifra que corres-
ponde al $77 \%$ de los participantes) y 15 de ellos
reportaron el uso de anticonceptivos. De las 14
mujeres participantes, diez afirmaron haber co-
menzado relaciones sexuales, , mientras que de
los ocho hombres participantes, siete afirmaron
tener relaciones sexuales.
Los anticonceptivos más usados por la población
entrevistada son el condón y métodos orales. El
primero es preferido por los varones y el segun-
do por las mujeres. Las razones argumentadas
para la elección del anticonceptivo son variadas:
desde la seguridad que ofrece el método para no
tener hijos, la recomendación médica, la facili-
dad de conseguirlos y usarlos hasta el control que
brindan y su popularidad.
Percepciones emergentes \\ La primera parte de los resultados corresponde a
la caracterización por edad y sexo de los partici-
pantes en la investigación. Fueron entrevistados
un total de 22 estudiantes de una universidad pri-
vada, matriculados para el segundo semestre del
año 2019 en las carreras de Licenciatura en Peda-
gogía Infantil, Enfermería, Derecho, Psicología
e Ingeniería Eléctrica. Ocho de los entrevistados
fueron hombres (36\%) y 14 mujeres (64\%), con
edades entre los 17 y 28 años, siendo la edad más
frecuente los 19 años cumplidos.
Se describió también el inicio de relaciones se-
xuales y uso de anticonceptivos de los y las par-
ticipantes; de los 22 entrevistados, 17 afirmaron
haber iniciado su vida sexual (cifra que corres-
ponde al $77 \%$ de los participantes) y 15 de ellos
reportaron el uso de anticonceptivos. De las 14
mujeres participantes, diez afirmaron haber co-
menzado relaciones sexuales, , mientras que de
los ocho hombres participantes, siete afirmaron
tener relaciones sexuales.
Los anticonceptivos más usados por la población
entrevistada son el condón y métodos orales. El
primero es preferido por los varones y el segun-
do por las mujeres. Las razones argumentadas
para la elección del anticonceptivo son variadas:
desde la seguridad que ofrece el método para no
tener hijos, la recomendación médica, la facili-
dad de conseguirlos y usarlos hasta el control que
brindan y su popularidad.
Percepciones emergentes \\ La primera parte de los resultados corresponde a
la caracterización por edad y sexo de los partici-
pantes en la investigación. Fueron entrevistados
un total de 22 estudiantes de una universidad pri-
vada, matriculados para el segundo semestre del
año 2019 en las carreras de Licenciatura en Peda-
gogía Infantil, Enfermería, Derecho, Psicología
e Ingeniería Eléctrica. Ocho de los entrevistados
fueron hombres (36\%) y 14 mujeres (64\%), con
edades entre los 17 y 28 años, siendo la edad más
frecuente los 19 años cumplidos.
Se describió también el inicio de relaciones se-
xuales y uso de anticonceptivos de los y las par-
ticipantes; de los 22 entrevistados, 17 afirmaron
haber iniciado su vida sexual (cifra que corres-
ponde al $77 \%$ de los participantes) y 15 de ellos
reportaron el uso de anticonceptivos. De las 14
mujeres participantes, diez afirmaron haber co-
menzado relaciones sexuales, , mientras que de
los ocho hombres participantes, siete afirmaron
tener relaciones sexuales.
Los anticonceptivos más usados por la población
entrevistada son el condón y métodos orales. El
primero es preferido por los varones y el segun-
do por las mujeres. Las razones argumentadas
para la elección del anticonceptivo son variadas:
desde la seguridad que ofrece el método para no
tener hijos, la recomendación médica, la facili-
dad de conseguirlos y usarlos hasta el control que
brindan y su popularidad.
Percepciones emergentes \\ La primera parte de los resultados corresponde a
la caracterización por edad y sexo de los partici-
pantes en la investigación. Fueron entrevistados
un total de 22 estudiantes de una universidad pri-
vada, matriculados para el segundo semestre del
año 2019 en las carreras de Licenciatura en Peda-
gogía Infantil, Enfermería, Derecho, Psicología
e Ingeniería Eléctrica. Ocho de los entrevistados
fueron hombres (36\%) y 14 mujeres (64\%), con
edades entre los 17 y 28 años, siendo la edad más
frecuente los 19 años cumplidos.
Se describió también el inicio de relaciones se-
xuales y uso de anticonceptivos de los y las par-
ticipantes; de los 22 entrevistados, 17 afirmaron
haber iniciado su vida sexual (cifra que corres-
ponde al $77 \%$ de los participantes) y 15 de ellos
reportaron el uso de anticonceptivos. De las 14
mujeres participantes, diez afirmaron haber co-
menzado relaciones sexuales, , mientras que de
los ocho hombres participantes, siete afirmaron
tener relaciones sexuales.
Los anticonceptivos más usados por la población
entrevistada son el condón y métodos orales. El
primero es preferido por los varones y el segun-
do por las mujeres. Las razones argumentadas
para la elección del anticonceptivo son variadas:
desde la seguridad que ofrece el método para no
tener hijos, la recomendación médica, la facili-
dad de conseguirlos y usarlos hasta el control que
brindan y su popularidad.
Percepciones emergentes \\ La primera parte de los resultados corresponde a
la caracterización por edad y sexo de los partici-
pantes en la investigación. Fueron entrevistados
un total de 22 estudiantes de una universidad pri-
vada, matriculados para el segundo semestre del
año 2019 en las carreras de Licenciatura en Peda-
gogía Infantil, Enfermería, Derecho, Psicología
e Ingeniería Eléctrica. Ocho de los entrevistados
fueron hombres (36\%) y 14 mujeres (64\%), con
edades entre los 17 y 28 años, siendo la edad más
frecuente los 19 años cumplidos.
Se describió también el inicio de relaciones se-
xuales y uso de anticonceptivos de los y las par-
ticipantes; de los 22 entrevistados, 17 afirmaron
haber iniciado su vida sexual (cifra que corres-
ponde al $77 \%$ de los participantes) y 15 de ellos
reportaron el uso de anticonceptivos. De las 14
mujeres participantes, diez afirmaron haber co-
menzado relaciones sexuales, , mientras que de
los ocho hombres participantes, siete afirmaron
tener relaciones sexuales.
Los anticonceptivos más usados por la población
entrevistada son el condón y métodos orales. El
primero es preferido por los varones y el segun-
do por las mujeres. Las razones argumentadas
para la elección del anticonceptivo son variadas:
desde la seguridad que ofrece el método para no
tener hijos, la recomendación médica, la facili-
dad de conseguirlos y usarlos hasta el control que
brindan y su popularidad.
Percepciones emergentes \\ La primera parte de los resultados corresponde a
la caracterización por edad y sexo de los partici-
pantes en la investigación. Fueron entrevistados
un total de 22 estudiantes de una universidad pri-
vada, matriculados para el segundo semestre del
año 2019 en las carreras de Licenciatura en Peda-
gogía Infantil, Enfermería, Derecho, Psicología
e Ingeniería Eléctrica. Ocho de los entrevistados
fueron hombres (36\%) y 14 mujeres (64\%), con
edades entre los 17 y 28 años, siendo la edad más
frecuente los 19 años cumplidos.
Se describió también el inicio de relaciones se-
xuales y uso de anticonceptivos de los y las par-
ticipantes; de los 22 entrevistados, 17 afirmaron
haber iniciado su vida sexual (cifra que corres-
ponde al $77 \%$ de los participantes) y 15 de ellos
reportaron el uso de anticonceptivos. De las 14
mujeres participantes, diez afirmaron haber co-
menzado relaciones sexuales, , mientras que de
los ocho hombres participantes, siete afirmaron
tener relaciones sexuales.
Los anticonceptivos más usados por la población
entrevistada son el condón y métodos orales. El
primero es preferido por los varones y el segun-
do por las mujeres. Las razones argumentadas
para la elección del anticonceptivo son variadas:
desde la seguridad que ofrece el método para no
tener hijos, la recomendación médica, la facili-
dad de conseguirlos y usarlos hasta el control que
brindan y su popularidad.
Percepciones emergentes \\ La primera parte de los resultados corresponde a
la caracterización por edad y sexo de los partici-
pantes en la investigación. Fueron entrevistados
un total de 22 estudiantes de una universidad pri-
vada, matriculados para el segundo semestre del
año 2019 en las carreras de Licenciatura en Peda-
gogía Infantil, Enfermería, Derecho, Psicología
e Ingeniería Eléctrica. Ocho de los entrevistados
fueron hombres (36\%) y 14 mujeres (64\%), con
edades entre los 17 y 28 años, siendo la edad más
frecuente los 19 años cumplidos.
Se describió también el inicio de relaciones se-
xuales y uso de anticonceptivos de los y las par-
ticipantes; de los 22 entrevistados, 17 afirmaron
haber iniciado su vida sexual (cifra que corres-
ponde al $77 \%$ de los participantes) y 15 de ellos
reportaron el uso de anticonceptivos. De las 14
mujeres participantes, diez afirmaron haber co-
menzado relaciones sexuales, , mientras que de
los ocho hombres participantes, siete afirmaron
tener relaciones sexuales.
Los anticonceptivos más usados por la población
entrevistada son el condón y métodos orales. El
primero es preferido por los varones y el segun-
do por las mujeres. Las razones argumentadas
para la elección del anticonceptivo son variadas:
desde la seguridad que ofrece el método para no
tener hijos, la recomendación médica, la facili-
dad de conseguirlos y usarlos hasta el control que
brindan y su popularidad.
Percepciones emergentes \\ La primera parte de los resultados corresponde a
la caracterización por edad y sexo de los partici-
pantes en la investigación. Fueron entrevistados
un total de 22 estudiantes de una universidad pri-
vada, matriculados para el segundo semestre del
año 2019 en las carreras de Licenciatura en Peda-
gogía Infantil, Enfermería, Derecho, Psicología
e Ingeniería Eléctrica. Ocho de los entrevistados
fueron hombres (36\%) y 14 mujeres (64\%), con
edades entre los 17 y 28 años, siendo la edad más
frecuente los 19 años cumplidos.
Se describió también el inicio de relaciones se-
xuales y uso de anticonceptivos de los y las par-
ticipantes; de los 22 entrevistados, 17 afirmaron
haber iniciado su vida sexual (cifra que corres-
ponde al $77 \%$ de los participantes) y 15 de ellos
reportaron el uso de anticonceptivos. De las 14
mujeres participantes, diez afirmaron haber co-
menzado relaciones sexuales, , mientras que de
los ocho hombres participantes, siete afirmaron
tener relaciones sexuales.
Los anticonceptivos más usados por la población
entrevistada son el condón y métodos orales. El
primero es preferido por los varones y el segun-
do por las mujeres. Las razones argumentadas
para la elección del anticonceptivo son variadas:
desde la seguridad que ofrece el método para no
tener hijos, la recomendación médica, la facili-
dad de conseguirlos y usarlos hasta el control que
brindan y su popularidad.
Percepciones emergentes \\ La primera parte de los resultados corresponde a
la caracterización por edad y sexo de los partici-
pantes en la investigación. Fueron entrevistados
un total de 22 estudiantes de una universidad pri-
vada, matriculados para el segundo semestre del
año 2019 en las carreras de Licenciatura en Peda-
gogía Infantil, Enfermería, Derecho, Psicología
e Ingeniería Eléctrica. Ocho de los entrevistados
fueron hombres (36\%) y 14 mujeres (64\%), con
edades entre los 17 y 28 años, siendo la edad más
frecuente los 19 años cumplidos.
Se describió también el inicio de relaciones se-
xuales y uso de anticonceptivos de los y las par-
ticipantes; de los 22 entrevistados, 17 afirmaron
haber iniciado su vida sexual (cifra que corres-
ponde al $77 \%$ de los participantes) y 15 de ellos
reportaron el uso de anticonceptivos. De las 14
mujeres participantes, diez afirmaron haber co-
menzado relaciones sexuales, , mientras que de
los ocho hombres participantes, siete afirmaron
tener relaciones sexuales.
Los anticonceptivos más usados por la población
entrevistada son el condón y métodos orales. El
primero es preferido por los varones y el segun-
do por las mujeres. Las razones argumentadas
para la elección del anticonceptivo son variadas:
desde la seguridad que ofrece el método para no
tener hijos, la recomendación médica, la facili-
dad de conseguirlos y usarlos hasta el control que
brindan y su popularidad.
Percepciones emergentes \\ La primera parte de los resultados corresponde a
la caracterización por edad y sexo de los partici-
pantes en la investigación. Fueron entrevistados
un total de 22 estudiantes de una universidad pri-
vada, matriculados para el segundo semestre del
año 2019 en las carreras de Licenciatura en Peda-
gogía Infantil, Enfermería, Derecho, Psicología
e Ingeniería Eléctrica. Ocho de los entrevistados
fueron hombres (36\%) y 14 mujeres (64\%), con
edades entre los 17 y 28 años, siendo la edad más
frecuente los 19 años cumplidos.
Se describió también el inicio de relaciones se-
xuales y uso de anticonceptivos de los y las par-
ticipantes; de los 22 entrevistados, 17 afirmaron
haber iniciado su vida sexual (cifra que corres-
ponde al $77 \%$ de los participantes) y 15 de ellos
reportaron el uso de anticonceptivos. De las 14
mujeres participantes, diez afirmaron haber co-
menzado relaciones sexuales, , mientras que de
los ocho hombres participantes, siete afirmaron
tener relaciones sexuales.
Los anticonceptivos más usados por la población
entrevistada son el condón y métodos orales. El
primero es preferido por los varones y el segun-
do por las mujeres. Las razones argumentadas
para la elección del anticonceptivo son variadas:
desde la seguridad que ofrece el método para no
tener hijos, la recomendación médica, la facili-
dad de conseguirlos y usarlos hasta el control que
brindan y su popularidad.
Percepciones emergentes \\ La primera parte de los resultados corresponde a
la caracterización por edad y sexo de los partici-
pantes en la investigación. Fueron entrevistados
un total de 22 estudiantes de una universidad pri-
vada, matriculados para el segundo semestre del
año 2019 en las carreras de Licenciatura en Peda-
gogía Infantil, Enfermería, Derecho, Psicología
e Ingeniería Eléctrica. Ocho de los entrevistados
fueron hombres (36\%) y 14 mujeres (64\%), con
edades entre los 17 y 28 años, siendo la edad más
frecuente los 19 años cumplidos.
Se describió también el inicio de relaciones se-
xuales y uso de anticonceptivos de los y las par-
ticipantes; de los 22 entrevistados, 17 afirmaron
haber iniciado su vida sexual (cifra que corres-
ponde al $77 \%$ de los participantes) y 15 de ellos
reportaron el uso de anticonceptivos. De las 14
mujeres participantes, diez afirmaron haber co-
menzado relaciones sexuales, , mientras que de
los ocho hombres participantes, siete afirmaron
tener relaciones sexuales.
Los anticonceptivos más usados por la población
entrevistada son el condón y métodos orales. El
primero es preferido por los varones y el segun-
do por las mujeres. Las razones argumentadas
para la elección del anticonceptivo son variadas:
desde la seguridad que ofrece el método para no
tener hijos, la recomendación médica, la facili-
dad de conseguirlos y usarlos hasta el control que
brindan y su popularidad.
Percepciones emergentes \\ La primera parte de los resultados corresponde a
la caracterización por edad y sexo de los partici-
pantes en la investigación. Fueron entrevistados
un total de 22 estudiantes de una universidad pri-
vada, matriculados para el segundo semestre del
año 2019 en las carreras de Licenciatura en Peda-
gogía Infantil, Enfermería, Derecho, Psicología
e Ingeniería Eléctrica. Ocho de los entrevistados
fueron hombres (36\%) y 14 mujeres (64\%), con
edades entre los 17 y 28 años, siendo la edad más
frecuente los 19 años cumplidos.
Se describió también el inicio de relaciones se-
xuales y uso de anticonceptivos de los y las par-
ticipantes; de los 22 entrevistados, 17 afirmaron
haber iniciado su vida sexual (cifra que corres-
ponde al $77 \%$ de los participantes) y 15 de ellos
reportaron el uso de anticonceptivos. De las 14
mujeres participantes, diez afirmaron haber co-
menzado relaciones sexuales, , mientras que de
los ocho hombres participantes, siete afirmaron
tener relaciones sexuales.
Los anticonceptivos más usados por la población
entrevistada son el condón y métodos orales. El
primero es preferido por los varones y el segun-
do por las mujeres. Las razones argumentadas
para la elección del anticonceptivo son variadas:
desde la seguridad que ofrece el método para no
tener hijos, la recomendación médica, la facili-
dad de conseguirlos y usarlos hasta el control que
brindan y su popularidad.
Percepciones emergentes \\ La primera parte de los resultados corresponde a
la caracterización por edad y sexo de los partici-
pantes en la investigación. Fueron entrevistados
un total de 22 estudiantes de una universidad pri-
vada, matriculados para el segundo semestre del
año 2019 en las carreras de Licenciatura en Peda-
gogía Infantil, Enfermería, Derecho, Psicología
e Ingeniería Eléctrica. Ocho de los entrevistados
fueron hombres (36\%) y 14 mujeres (64\%), con
edades entre los 17 y 28 años, siendo la edad más
frecuente los 19 años cumplidos.
Se describió también el inicio de relaciones se-
xuales y uso de anticonceptivos de los y las par-
ticipantes; de los 22 entrevistados, 17 afirmaron
haber iniciado su vida sexual (cifra que corres-
ponde al $77 \%$ de los participantes) y 15 de ellos
reportaron el uso de anticonceptivos. De las 14
mujeres participantes, diez afirmaron haber co-
menzado relaciones sexuales, , mientras que de
los ocho hombres participantes, siete afirmaron
tener relaciones sexuales.
Los anticonceptivos más usados por la población
entrevistada son el condón y métodos orales. El
primero es preferido por los varones y el segun-
do por las mujeres. Las razones argumentadas
para la elección del anticonceptivo son variadas:
desde la seguridad que ofrece el método para no
tener hijos, la recomendación médica, la facili-
dad de conseguirlos y usarlos hasta el control que
brindan y su popularidad.
Percepciones emergentes \\ La primera parte de los resultados corresponde a
la caracterización por edad y sexo de los partici-
pantes en la investigación. Fueron entrevistados
un total de 22 estudiantes de una universidad pri-
vada, matriculados para el segundo semestre del
año 2019 en las carreras de Licenciatura en Peda-
gogía Infantil, Enfermería, Derecho, Psicología
e Ingeniería Eléctrica. Ocho de los entrevistados
fueron hombres (36\%) y 14 mujeres (64\%), con
edades entre los 17 y 28 años, siendo la edad más
frecuente los 19 años cumplidos.
Se describió también el inicio de relaciones se-
xuales y uso de anticonceptivos de los y las par-
ticipantes; de los 22 entrevistados, 17 afirmaron
haber iniciado su vida sexual (cifra que corres-
ponde al $77 \%$ de los participantes) y 15 de ellos
reportaron el uso de anticonceptivos. De las 14
mujeres participantes, diez afirmaron haber co-
menzado relaciones sexuales, , mientras que de
los ocho hombres participantes, siete afirmaron
tener relaciones sexuales.
Los anticonceptivos más usados por la población
entrevistada son el condón y métodos orales. El
primero es preferido por los varones y el segun-
do por las mujeres. Las razones argumentadas
para la elección del anticonceptivo son variadas:
desde la seguridad que ofrece el método para no
tener hijos, la recomendación médica, la facili-
dad de conseguirlos y usarlos hasta el control que
brindan y su popularidad.
Percepciones emergentes \\ La primera parte de los resultados corresponde a
la caracterización por edad y sexo de los partici-
pantes en la investigación. Fueron entrevistados
un total de 22 estudiantes de una universidad pri-
vada, matriculados para el segundo semestre del
año 2019 en las carreras de Licenciatura en Peda-
gogía Infantil, Enfermería, Derecho, Psicología
e Ingeniería Eléctrica. Ocho de los entrevistados
fueron hombres (36\%) y 14 mujeres (64\%), con
edades entre los 17 y 28 años, siendo la edad más
frecuente los 19 años cumplidos.
Se describió también el inicio de relaciones se-
xuales y uso de anticonceptivos de los y las par-
ticipantes; de los 22 entrevistados, 17 afirmaron
haber iniciado su vida sexual (cifra que corres-
ponde al $77 \%$ de los participantes) y 15 de ellos
reportaron el uso de anticonceptivos. De las 14
mujeres participantes, diez afirmaron haber co-
menzado relaciones sexuales, , mientras que de
los ocho hombres participantes, siete afirmaron
tener relaciones sexuales.
Los anticonceptivos más usados por la población
entrevistada son el condón y métodos orales. El
primero es preferido por los varones y el segun-
do por las mujeres. Las razones argumentadas
para la elección del anticonceptivo son variadas:
desde la seguridad que ofrece el método para no
tener hijos, la recomendación médica, la facili-
dad de conseguirlos y usarlos hasta el control que
brindan y su popularidad.
Percepciones emergentes \\ La primera parte de los resultados corresponde a
la caracterización por edad y sexo de los partici-
pantes en la investigación. Fueron entrevistados
un total de 22 estudiantes de una universidad pri-
vada, matriculados para el segundo semestre del
año 2019 en las carreras de Licenciatura en Peda-
gogía Infantil, Enfermería, Derecho, Psicología
e Ingeniería Eléctrica. Ocho de los entrevistados
fueron hombres (36\%) y 14 mujeres (64\%), con
edades entre los 17 y 28 años, siendo la edad más
frecuente los 19 años cumplidos.
Se describió también el inicio de relaciones se-
xuales y uso de anticonceptivos de los y las par-
ticipantes; de los 22 entrevistados, 17 afirmaron
haber iniciado su vida sexual (cifra que corres-
ponde al $77 \%$ de los participantes) y 15 de ellos
reportaron el uso de anticonceptivos. De las 14
mujeres participantes, diez afirmaron haber co-
menzado relaciones sexuales, , mientras que de
los ocho hombres participantes, siete afirmaron
tener relaciones sexuales.
Los anticonceptivos más usados por la población
entrevistada son el condón y métodos orales. El
primero es preferido por los varones y el segun-
do por las mujeres. Las razones argumentadas
para la elección del anticonceptivo son variadas:
desde la seguridad que ofrece el método para no
tener hijos, la recomendación médica, la facili-
dad de conseguirlos y usarlos hasta el control que
brindan y su popularidad.
Percepciones emergentes \\ La primera parte de los resultados corresponde a
la caracterización por edad y sexo de los partici-
pantes en la investigación. Fueron entrevistados
un total de 22 estudiantes de una universidad pri-
vada, matriculados para el segundo semestre del
año 2019 en las carreras de Licenciatura en Peda-
gogía Infantil, Enfermería, Derecho, Psicología
e Ingeniería Eléctrica. Ocho de los entrevistados
fueron hombres (36\%) y 14 mujeres (64\%), con
edades entre los 17 y 28 años, siendo la edad más
frecuente los 19 años cumplidos.
Se describió también el inicio de relaciones se-
xuales y uso de anticonceptivos de los y las par-
ticipantes; de los 22 entrevistados, 17 afirmaron
haber iniciado su vida sexual (cifra que corres-
ponde al $77 \%$ de los participantes) y 15 de ellos
reportaron el uso de anticonceptivos. De las 14
mujeres participantes, diez afirmaron haber co-
menzado relaciones sexuales, , mientras que de
los ocho hombres participantes, siete afirmaron
tener relaciones sexuales.
Los anticonceptivos más usados por la población
entrevistada son el condón y métodos orales. El
primero es preferido por los varones y el segun-
do por las mujeres. Las razones argumentadas
para la elección del anticonceptivo son variadas:
desde la seguridad que ofrece el método para no
tener hijos, la recomendación médica, la facili-
dad de conseguirlos y usarlos hasta el control que
brindan y su popularidad.
Percepciones emergentes \\ La primera parte de los resultados corresponde a
la caracterización por edad y sexo de los partici-
pantes en la investigación. Fueron entrevistados
un total de 22 estudiantes de una universidad pri-
vada, matriculados para el segundo semestre del
año 2019 en las carreras de Licenciatura en Peda-
gogía Infantil, Enfermería, Derecho, Psicología
e Ingeniería Eléctrica. Ocho de los entrevistados
fueron hombres (36\%) y 14 mujeres (64\%), con
edades entre los 17 y 28 años, siendo la edad más
frecuente los 19 años cumplidos.
Se describió también el inicio de relaciones se-
xuales y uso de anticonceptivos de los y las par-
ticipantes; de los 22 entrevistados, 17 afirmaron
haber iniciado su vida sexual (cifra que corres-
ponde al $77 \%$ de los participantes) y 15 de ellos
reportaron el uso de anticonceptivos. De las 14
mujeres participantes, diez afirmaron haber co-
menzado relaciones sexuales, , mientras que de
los ocho hombres participantes, siete afirmaron
tener relaciones sexuales.
Los anticonceptivos más usados por la población
entrevistada son el condón y métodos orales. El
primero es preferido por los varones y el segun-
do por las mujeres. Las razones argumentadas
para la elección del anticonceptivo son variadas:
desde la seguridad que ofrece el método para no
tener hijos, la recomendación médica, la facili-
dad de conseguirlos y usarlos hasta el control que
brindan y su popularidad.
Percepciones emergentes \\ La primera parte de los resultados corresponde a
la caracterización por edad y sexo de los partici-
pantes en la investigación. Fueron entrevistados
un total de 22 estudiantes de una universidad pri-
vada, matriculados para el segundo semestre del
año 2019 en las carreras de Licenciatura en Peda-
gogía Infantil, Enfermería, Derecho, Psicología
e Ingeniería Eléctrica. Ocho de los entrevistados
fueron hombres (36\%) y 14 mujeres (64\%), con
edades entre los 17 y 28 años, siendo la edad más
frecuente los 19 años cumplidos.
Se describió también el inicio de relaciones se-
xuales y uso de anticonceptivos de los y las par-
ticipantes; de los 22 entrevistados, 17 afirmaron
haber iniciado su vida sexual (cifra que corres-
ponde al $77 \%$ de los participantes) y 15 de ellos
reportaron el uso de anticonceptivos. De las 14
mujeres participantes, diez afirmaron haber co-
menzado relaciones sexuales, , mientras que de
los ocho hombres participantes, siete afirmaron
tener relaciones sexuales.
Los anticonceptivos más usados por la población
entrevistada son el condón y métodos orales. El
primero es preferido por los varones y el segun-
do por las mujeres. Las razones argumentadas
para la elección del anticonceptivo son variadas:
desde la seguridad que ofrece el método para no
tener hijos, la recomendación médica, la facili-
dad de conseguirlos y usarlos hasta el control que
brindan y su popularidad.
Percepciones emergentes \\ La primera parte de los resultados corresponde a
la caracterización por edad y sexo de los partici-
pantes en la investigación. Fueron entrevistados
un total de 22 estudiantes de una universidad pri-
vada, matriculados para el segundo semestre del
año 2019 en las carreras de Licenciatura en Peda-
gogía Infantil, Enfermería, Derecho, Psicología
e Ingeniería Eléctrica. Ocho de los entrevistados
fueron hombres (36\%) y 14 mujeres (64\%), con
edades entre los 17 y 28 años, siendo la edad más
frecuente los 19 años cumplidos.
Se describió también el inicio de relaciones se-
xuales y uso de anticonceptivos de los y las par-
ticipantes; de los 22 entrevistados, 17 afirmaron
haber iniciado su vida sexual (cifra que corres-
ponde al $77 \%$ de los participantes) y 15 de ellos
reportaron el uso de anticonceptivos. De las 14
mujeres participantes, diez afirmaron haber co-
menzado relaciones sexuales, , mientras que de
los ocho hombres participantes, siete afirmaron
tener relaciones sexuales.
Los anticonceptivos más usados por la población
entrevistada son el condón y métodos orales. El
primero es preferido por los varones y el segun-
do por las mujeres. Las razones argumentadas
para la elección del anticonceptivo son variadas:
desde la seguridad que ofrece el método para no
tener hijos, la recomendación médica, la facili-
dad de conseguirlos y usarlos hasta el control que
brindan y su popularidad.
Percepciones emergentes}




\section{Yenny Patricia Moreno-Rangel, Edgar Alexander Rincón-Silva}

ISSN-PRINT

1794-9831

E-ISSN 2322-7028

Vol. 17 No. 3

Sep - Dic 2020

Cúcuta, Colombia
No obstante, la paternidad quedó asociada de manera enfática al proyecto de vida en el mediano y largo plazo. Ningún hombre manifestó una percepción favorable a la paternidad en la adolescencia tardía (de 18 a 21 años) o en la etapa universitaria.

Las afirmaciones del participante 11 nos ofrecen un ejemplo claro de este orden de metas y la priorización del logro académico en el corto plazo: "Si [imagino ser padre] pero para ese entonces espero ya haber formalizado mi vida con alguien [...] no me veo siéndolo ahora pues hasta ahora inicié mi rol de estudiante y pues imagínate sería un impacto terrible serlo así como solo por desliz entonces no, prefiero ir con calma culminar mis estudios y luego formar familia, hacer las cosas bien".

El participante 10, hizo énfasis en la necesidad de asegurar una estabilidad económica antes de pensar en la paternidad: "Sí [deseo ser padre] pero más adelante en unos años cuando tenga una estabilidad económica, porque un niño es un gasto considerable, grande, o sea la pediatría, pañales, cuidados...".

Similar posición planteó el entrevistado 9 quien afirmó frente a tener hijos que: "si me gustaría, pero en este momento no, cada aspecto viene en un momento especifico de la vida, me gustaría lograr enfocar bien el ser buen emprendedor y tener buenos recursos para poder mantenerlos".

\section{Maternidad en el proyecto de vida de las mujeres entrevistadas.}

Algunas mujeres fueron enfáticas en el logro de la vida profesional como un paso indispensable antes de pensar en la maternidad, otras incluso manifestaron no sólo la postergación de la maternidad sino su exclusión de su plan de vida: no deseaban tener hijos, conformar una familia o contraer matrimonio, con respecto a eso una de las participantes afirmaba que: "no siento que sea una obligación que para ser mujer y sentirme empoderada tenga que ya haber tenido un bebe o una niña o un niño". ( Participante 12). Otra participante decía que, "pues también no es obligación, digamos uno como mujer tener un hijo, yo no sé, nunca he tenido ese concepto". (Participante 18)

En otras palabras, el mundo femenino de las par- ticipantes no busca girar en torno a los hijos y la maternidad como generador de identidad y sentido de vida.

Por ejemplo, una estudiante manifestó que se imaginaba a corto plazo "principalmente terminando la universidad y especializándome en materias relacionadas con lo que estudié. En mi casa con mis papás. No tengo planes de tener esposo ni nada de eso, ni con hijos ni nada, netamente en mi carrera". (Participante 3).

Sin embargo una gran parte de las mujeres entrevistadas refieren desear una pareja estable y tener hijos dentro de sus expectativas. Una de ellas habló de matrimonio al finalizar la meta de la graduación: "me veo ya en planes de casarme con mi pareja y más adelante tener hijos" (Participante 6).

También se identifica un tercer grupo de mujeres que están en la ambivalencia: "de pronto en cinco años si de pronto estar con un persona un poco más estable para que sea un apoyo, también para adquirir esos sueños, pero si hasta el momento en esos cinco años no ha llegado una persona que me ayude a crecer, pues considero que de pronto seguiría creciendo sola" (Particpante 4).

Finalmente se presenta a grandes rasgos el deseo de las entrevistadas de posponer la maternidad asociado a las expectativas del entorno social y las representaciones derivadas de las experiencias personales: algunos jóvenes afirman ser primordial "ayudar a la familia" o "ayudar a sus padres" antes que tener hijos o hijas. Otras, que "por su experiencia familiar" reconocían que criar un hijo en la juventud "... era muy complicado... quitaba mucho tiempo y no era nada fácil". (Participantes 3,6 y 8).

\section{Construcciones hegemónicas de género frente a la maternidad y la paternidad.}

La maternidad y la paternidad constituyen construcciones simbólicas relativizadas por lo histórico y lo sociocultural que poseen dimensiones subjetivas abordables desde la salud integral (2526).

Frente a las definiciones de paternidad y de maternidad es necesario establecer que indudablemente ha habido una evolución que poco a poco ha desnaturalizado los roles históricamente construidos, manifestado por las participantes en frases como "hace 30- 40 años se tenía un concepto claro de qué era familia... la mujer quedaba en 
embarazo, el hombre asumía su papel responsablemente, respondia por su familia y la mamita se dedicaba solamente a su hogar y a sus hijos..." (Participante 16).

Sin embargo algunos de los participantes continúan dándole una mayor preponderancia a la maternidad como destino de las mujeres, y esto se demuestra en frases como:

"Ser madre es lo que se espera de toda mujer, es como parte de su razón de ser" (Participante 22). "...yo siempre he soñado con ser mamá, pues me gustaría mucho, sería súper amorosa, que me tengan confianza..." (Participante 22).

Esto contrasta con las visiones negativas de la paternidad actual, especialmente desde la visión de varias participantes quienes consideran que, aunque una paternidad responsable y diligente es lo deseable y algunos hombres son "buenos padres", es más frecuente el abandono, la falta de "responsabilidad" y de preocupación frente a la crianza, labor que termina recargada en la energía y tiempo de la madre:

"he visto los casos donde la chica se embaraza, de pronto el papá no le responde y se va [...] a ellos como que en algunos casos no sienten de verdad que es su responsabilidad. [Ellos] no tienen que estar con su bebé, si cuando se enferman, no tienen que estar pendiente del colegio, de que hagan las tareas, ósea yo siempre veo que es la mamá que tiene su mayor grado de responsabilidad" (Participante 2).

Otra estudiante afirmó que: "son muchos casos en los que uno ve las chicas que tienen que salir adelante solas como mamás solteras [...] y los papás (del bebé) pagándoles unas cuotas que les ponen y ellos libres con su vida, siguen normal y pues sí tienen un hijo, pero pues si le pagan 35 mil mensuales y verán la mamás cómo se defienden" (Participante 1).

Se les asigna una mayor responsabilidad a las mujeres debido a la construcción social de los roles de género, indicando que la mujer es por "naturaleza" maternal y que tiene un "instinto" que la ayuda a realizar mejor las labores del cuidado y de las labores domésticas y está tan arraigado en las personas que naturalizan estos patrones, lo cual se puede valorar en situaciones descritas como las siguientes:

"Por lo general las mamás siempre son las que asumen la responsabilidad, que la mamá en la casa o cuando se separan las mamás son las que se quedan con los hijos, entonces siempre las mamás tienen como más responsabilidad sobre los hijos..." (Participante 20.)

"La paternidad pues igualmente es de mucha responsabilidad, pero pues según lo que he visto y lo que he podido darme cuenta no es tanto como la maternidad". (Participante 15.)

\section{Discusión}

Los resultados del estudio determinan que la educación se está convirtiendo en la prioridad dentro de la elaboración del proyecto de vida de las y los jóvenes, especialmente una noción de mujer educada, empoderada, ciudadana y trabajadora ha venido ganando espacio socialmente.

Muchos de los participantes prefieren su avance profesional y económico a la conformación inmediata de una familia, lo cual coincide con los datos arrojados por el Observatorio de Igualdad de Género de América Latina y el Caribe de la CEPAL que da cuenta de que la tasa de participación laboral de la mujer superó por primera vez el 50 por ciento del total (27).

En cuanto a los hallazgos frente a la percepción del hombre como padre y desempeño de su rol, se nota una postura menos tradicional a la naturalizada como proveedor económico y trabajador que aporta elementos materiales y es jefe de hogar, visto además como reproductor, no siempre presente en la crianza de los hijos, hecho que puede sugerir la ruptura con la idea de paternidad poco activa o comprometida (28).

Esto puede ser evidencia de procesos de cambio y reconfiguración de la paternidad en relación con el espacio doméstico y la práctica del cuidado, con el deseo de cuidar del hijo (y considerar negativo que otro diferente al padre/madre sea quien lo haga) asociándolo a los espacios alcanzados por las mujeres y el consecuente reajuste social, así como a la promoción de nuevas masculinidades y de paternidades más activas o participativas desde políticas públicas (29-30).

De igual forma, tal como lo estableció un estudio con estudiantes de enfermería (31), los relatos de esta investigación muestran que en algunos casos, paulatinamente los jóvenes van superando los estereotipos de la maternidad/ paternidad tradicional, optando por posturas menos convencionales, decidiendo posponer su rol de padre/madre en sus proyectos de vida a corto y mediano plazo pues lo ven como una potencial barrera para la consecución de sus metas personales inmediatas.

Asumir esta elección está lejos de ser obvio, en 
un momento en que las tradiciones sociales y los dogmas religiosos todavía elogian la maternidad y es aún un anhelo social o familiar, que la mujer tenga hijos, debido a que la mujer históricamente ha sido valorada por su maternidad, mientras que en los varones no se considera la paternidad como complemento de masculinidad y se ha aceptado socialmente su ausencia en las labores del cuidado (32).

Esto se asemeja a los hallazgos de Arango (33), quien planteaba que "la mujer empieza a considerar la función materna como menos positiva y atractiva que en otras épocas". También concuerda con las conclusiones de Velázquez et al (34) quienes hallan que para los jóvenes en México ahora "el proyecto de paternidad/maternidad se inserta dentro de uno más amplio que posterga dicha realización a otros objetivos primordiales para los sujetos" como la finalización de estudios.

Con lo que es pertinente afirmar que como parte de la estructura social, el análisis de la materni$\mathrm{dad} /$ paternidad adolescente implica una aproximación multicausal debido a que es un fenómeno en donde convergen diversos factores: histórico, político, social, psicológico, económico, cultural, sexual, demográfico, entre otros. (25)

Precisamente, la maternidad es entendida por algunos autores como la representación cultural más compleja que sobre el imaginario de lo femenino se ha elaborado a lo largo de la historia. La maternidad puede encarnar una serie de ideales sociales que más allá de los discursos, se expresan en las exigencias que recaen sobre las mujeres y están atravesados por nociones de género, condiciones de socialización (35).

Todo lo anterior lleva a pensar que, para los estudiantes entrevistados, la experiencia del tener hijos o hijas se pospone, no solo por la ruptura definitiva con la tradición o porque haya una nueva lectura y presentación del ser mujer y hombre, sino porque la maternidad y paternidad también significa sacrificios y mayores responsabilidades (36).

Esta visión tiene una gran carga de roles de género tradicionales, pues las madres universitarias son representadas en el entorno como mujeres abnegadas, fuertes y luchadoras. Este fenómeno es prevalente en investigaciones previas que evidencian el papel de la cultura y la sociedad al moldear una imagen concreta del constructo paternidad o maternidad (34), sin embargo, autoras revelaron una paternidad asociada con sentimientos de ternura hacia los bebés, invitación al logro y la madurez; algo muy distante de la representación de la paternidad en nuestro contexto (9).

También es posible reconocer, tal como lo han expresado actuales indagaciones, que en la vida de las mujeres la tensión entre el peligro y el placer sexual es muy poderosa. La sexualidad es a la vez, un terreno de constreñimiento, de represión y peligro; y un terreno de exploración, placer y actuación. El deseo sexual femenino se constriñe a los campos que la cultura protege y favorece: el matrimonio tradicional y la familia nuclear (26,37).

De igual forma, en la presente investigación tal como describen Parada y García(38), se evidencia que aunque los adolescentes quisieran continuar con sus estudios, desafortunadamente hay pocas redes de apoyo familiar y social que impiden la compatibilización de su nuevo rol de padre/madre con su vida universitaria.

Los resultados también muestran que las jóvenes cuentan con alguna información sobre anticonceptivos, hay uso y se expresan percepciones positivas sobre los mismos. En este aspecto, resulta positivo y concordante con estudios que hallan alto uso de anticonceptivos entre la población participante $(34,39)$.

Sin embargo, el estudio muestra que persiste el uso de métodos de emergencia por parte de algunas participantes, lo que se correlaciona con establecimiento de relaciones sexuales sin protección, elemento que también ha sido evidenciado en otras investigaciones, ratificando que los conocimientos sobre anticoncepción no implican que se utilicen siempre los anticonceptivos adecuados (40-42).

Este elemento representa una pieza fundamental del estudio pues permite dilucidar que, no por el hecho de estar en la universidad y haber llegado a su mayoría de edad, tienen resuelta su educación sexual y es importante continuar con el acompañamiento a los jóvenes en materia de sexualidad pues el embarazo no planeado es un factor en la deserción escolar que actúa en detrimento de las mujeres a quienes se les exige mayores responsabilidades y juzga más duramente en estas situaciones (43).

En este sentido, varios estamentos recomiendan continuar con los programa y estrategias que permitan a los jóvenes universitarios tener acceso a educación y a salud sexual y reproductiva durante su formación profesional para evitar los embarazos no planeados y la consecuente deserción o atraso escolar (44-46). 


\section{Conclusiones}

- La postergación de la maternidad/paternidad parece indicar el cuestionamiento de los roles tradicionales y el lugar que ocupan en la vida de los jóvenes frente a lo laboral y académico.

- Las narraciones indican, aunque con menos frecuencia que antes, la presencia de patrones hegemónicos de género asociados a la maternidad y paternidad alimentados por percepciones idealizadas de la maternidad o influencias religiosas sobre la forma de ver el papel de la mujer, la madre y padre en el entorno.

- Los jóvenes cuentan con alguna información sobre anticonceptivos, hay uso y se expresan percepciones positivas sobre los mismos, pero es evidente que aún se presentan relaciones sexuales sin protección y que no hay una apropiación del uso de condón por parte de las mujeres.

- Los cambios sociales en la conformación de la familia han supuesto una recarga en el rol de la madre, no solamente como cuidadora sino también como proveedora. Las entrevistas evidencian que los participantes, especialmente las mujeres, son conscientes de ello y esperan contar con parejas masculinas más involucradas en la crianza y el cuidado.

\section{Limitaciones del estudio}

Dentro de las limitaciones tenemos el reducido número de entrevistados que no permite tener un panorama más amplio de este tema y generar resultados más precisos y generar una discusión más completa.

\section{Conflicto de intereses}

Los autores declaran que para el desarrollo del presente estudio no existió conflicto de intereses.

\section{Referencias bibliográficas}

1. Tinto V. Definir la desercion: Una cuestion de perspectiva. Rev Educ Super [Internet]. 1989 [Citado 3 febrero 2019]; 18(71):160. Disponible en: http://publicaciones.anuies. mx/pdfs/revista/Revista71 S1A3ES.pdf

2. Sánchez G, Navarro W, García A. Factores de Deserción Estudiantil en la Universidad Surcolombiana. Rev Paid Surcolombiana[Internet]. 2009 [Citado 30 noviembre 2018]; (14):97-103. Disponible en: https://doi.org/10.25054/01240307.1083

3. Lopez-Villafaña L, Beltrán-Solache A. La deserción en estudiantes de educación superior: tres percepciones en estudio, alumnos, docentes y padres de familia. Pist Educ [Internet]. 2017[Citado 10 enero 2020]; 39(126):143-159. Disponible en: http://www. itcelaya.edu.mx/ojs/index.php/pistas/article/view/776

4. Guzmán-Ruiz C, Muriel-Durán D, Franco-Gallego J. Deserción estudiantil en la educación superior colombiana. Metodología de seguimiento, diagnóstico y elementos para su prevención. Ministerio de Educación Nacional, Colombia. [Internet]. 2009 [Citado 30 mayo 2019]; 1-358 p. Disponible en: http://www.mineducacion.gov.co/sistemasdeinformacion/1735/articles-254702 libro desercion.pdf

5. Fernández-Hileman M, Corengia A, Durand J. Deserción y retención universitaria: una discusión bibliográfica. Rev pensando Psicol. [Internet]. 2014 [Citado 12 abril 2019]; 10(17):85-96. Disponible en: https://www.researchgate.net/deref/http $\% 3 \mathrm{~A} \% 2 \mathrm{~F} \% 2 \mathrm{Fdx}$. doi.org\%2F10.16925\%2Fpe.v10i17.787

6. Bouchard LC, Shih JH. Gender differences in stress generation: Examination of interpersonal predictors. J Soc Clin Psychol. [Internet]. 2013 [Citado 15 febrero 2019]; 32(4):424-45. Disponible en: https://guilfordjournals.com/doi/pdf/10.1521/ jscp.2013.32.4.424

7. Cai Z, Stephens HM, Winters JV. Motherhood, migration, and self-employment of college graduates. Small Bus Econ. [Internet]. 2019 [Citado 12 abril 2019]; 53(3):611-29. Disponible en: https://link-springer-com.ezproxy.unbosque.edu.co/article/10.1007/ 


\section{$\underline{\text { s11187-019-00177-2 }}$}

ISSN-PRINT

1794-9831

E-ISSN 2322-7028

Vol. 17 No. 3

Sep - Dic 2020

Cúcuta, Colombia

8. Rivera-Camargo M. Impacto de la educación superior en el desarrollo socio-económico de Colombia. [Internet]. 2019 [Citado 12 enero 2020]; 36p. Disponible en: https://core. ac.uk/download/pdf/286063064.pdf

9. Briones-Vega VJ, González-Araya JA. Jóvenes padres. Estudio exploratorio de paternidad en padres universitarios de la Pontificia Universidad Católica de Valparaíso. [Tesis en internet] Chile: Universidad Católica de Valparaís; 2015. [Citado 12 abril 2019]. Disponible en: http://opac.pucv.cl/pucv txt/txt-8000/UCE8458 01.pdf

10. Reina-Barreto JA, Criollo-Espín CA, Fernández-D’Andrea K. Apoyo social en la maternidad indeseada de estudiantes universitarias ecuatorianas: Análisis desde la perspectiva de género. Prospectiva. [Internet]. 2019 [Citado 15 febrero 2019]; 27:107-137. Disponible en: http://www.scielo.org.co/scielo.php?pid=S0122-12132019000100107\&scrip$\underline{\mathrm{t}=\mathrm{sci} \text { abstract\&tlng }=\mathrm{es}}$

11. Lafaurie MM, Valbuena Y. La pareja masculina en el embarazo: perspectiva de gestantes atendidas por la Subred Integrada de Servicios de Salud Norte. Bogotá. Rev Colomb Enfermería. [Internet]. 2018 [Citado 30 junio 2019]; 17(13):46-55. Disponible en: https://masd.unbosque.edu.co/index.php/RCE/article/view/2432

12. Hauser-Dacer J. Embarazo y Maternidad, las Desigualdades de Género y los Aportes del Arteterapia. Arteterapia Papeles arteterapia y Educ artística para la inclusión Soc. [Internet]. 2016 [Citado 15 febrero 2019]; 11(0):151-61. Disponible en: http://repositorio.uchile.cl/handle/2250/149116

13. Ministerio de Salud y Protección Social. Encuesta Nacional de Demografía y Salud Encuesta Nacional de Demografía y Salud Tomo I. [Internet]. 2017 [Citado 15 febrero 2019]; 430p. Disponible en: https://profamilia.org.co/wp-content/uploads/2018/12/ ENDS-TOMO-I.pdf

14. González E, Molina T, Luttges C. Características de la educación sexual escolar recibida y su asociación con la edad de inicio sexual y uso de anticon- ceptivos en adolescentes chilenas sexualmente activas. Rev Chil Obs Ginecol [Internet]. 2015 [Citado 15 marzo 2018]; 80(1):24-32. Disponible en: http://repositorio.uchile.cl/bitstream/handle/2250/137935/caracteristicas-de-la-educacion-sexual-escolar-recibida-y.pdf?sequen$\underline{\mathrm{ce}=1 \& \text { is Allowed }=\mathrm{y}}$

15. Berg R, Underland V. The effectiveness of health promotion and preventive interventions on nutrition, physical activity, obesity, and sexual health in children and adolescents. [Internet]. 2012 [Citado 10 junio 2018]. Disponible en: https://www.ncbi.nlm.nih. gov/books/NBK464780/

16. Vicario H. Adolescencia. Aspectos físicos, psicológicos y sociales. An Pediatr Contin. [Internet].2014 [Citado 12 noviembre 2019]; 12(1):42-46. Disponible en: http://biblioteca.iplacex.cl/RCA/Adolescencia. $\% 20$ Aspectos $\% 20 \mathrm{f} \% \mathrm{C} 3 \% \mathrm{ADsicos}, \% 20 \mathrm{psicol} \%$ C3\%B3gicos $\% 20 \mathrm{y} \% 20$ sociales.pdf

17. Hernández-Sampieri R, Baptista-Lucio P, Fernández-Collado C. Metodología de la Investigación. McGraw-Hill Interam. 2004. Disponible en https://www.esup.edu.pe/ descargas/dep investigacion/Metodologia $\% 20 \mathrm{de} \% 201 \mathrm{a} \% 20$ investigaci $\% \mathrm{C} 3 \% \mathrm{~B} 3 \mathrm{n} \% 20$ 5ta $\% 20$ Edici $\%$ C $3 \%$ B3n.pdf

18. Oberti A, Bacci C. Metodología de la investigación. Mem Académica [Internet]. 2016 [Citado 15 febrero 2019]. Disponible en: http://www.memoria.fahce.unlp.edu.ar/library? $\mathrm{a}=\mathrm{d} \& \mathrm{c}=$ progra\& $\mathrm{d}=\mathrm{Jpp} 10878$

19. Selma-Penalva A. La discriminación por maternidad y conciliación en el ámbito universitario. FEMERIS Rev Multidiscip Estud Género. [Internet]. 2019 [Citado 12 enero 2020]; 4(2):132. Disponible en: https://e-revistas.uc3m.es/index.php/FEMERIS/article/ view/4768 
20. Miller D, Arvizu V. Ser madre y estudiante. Una exploración de las características de las universitarias con hijos y breves notas para su estudio. Rev la Educ Super. [Internet]. 2016 [Citado 15 febrero 2019]; 45(177):17-42. Disponible en: http://www.scielo.org.

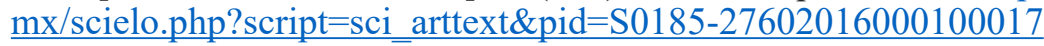

21. Peñaloza-Vergara LV, Estupiñán YP. Proyecto de vida en cuanto a las percepciones de la maternidad en mujeres de 14 a 19 años de edad, de educación media y un centro de atención para madres adolescentes. [Citado 10 enero 2019] Universidad San Buenaventura Cartagena; 2017. Disponible en: https://bibliotecadigital.usb.edu.co/bitstream $/ 10819 / 5994 / 1 /$ Proyecto $\% 20 \mathrm{de} \% 20$ vida $\% 20$ en $\% 20$ cuanto Laura $\% 20 \mathrm{Pe} \% \mathrm{C} 3 \%$ B1alosa\%20V 2017.pdf

22. Higgins JA, Hoffman S, Graham CA, Sanders SA. Relationships between condoms, hormonal methods, and sexual pleasure and satisfaction: An exploratory analysis from the women's well-being and sexuality study. Sex Health. [Internet]. 2008 [Citado 10 julio 2018]; 5(4):321-30. Disponible en: https:/www.publish.csiro.au/sh/SH08021

23. Higgins JA, Hirsch JS. Pleasure, power, and inequality: Incorporating sexuality into research on contraceptive use. Am J Public Health. [Internet]. 2008 [Citado 10 julio 2018]; 98(10):1803-13. Disponible en: https://ajph.aphapublications.org/doi/ full/10.2105/AJPH.2007.115790

24. República de Colombia. Ministerio de Salud. Resolución No 008430 de 1993, octubre 4, por la cual se establecen las normas científicas, técnicas y administrativas para la investigación en salud [Internet]. Santa Fe de Bogotá: El Ministerio; 1993 [consultado 30 de febrero de 2020]. Disponible en: https://www.minsalud.gov.co/sites/rid/Lists/BibliotecaDigital/RIDE/DE/DIJ/RESOLUCION-8430-DE-1993.pdf

25. Puyana-Villamizar Y, Mosquera-Rosero C. Traer "hijos o hijas al mundo": significados culturales de la paternidad y la maternidad. Rev Latinoam Ciencias Soc Niñez y Juv. [Internet]. 2005 [Citado 30 febrero 2020]; 3(2):111-140. Disponible en: http://www. scielo.org.co/scielo.php?pid=S1692-715X2005000200005\&script=sci arttext\&tlng=pt

26. Agudelo-Londoño J, Bedoya-García J, Osorio-Tamayo DL. Ser mujer: entre la maternidad y la identidad. Poiésis. [Internet]. 2016 [Citado 30 febrero 2020]; 31:306-313. Disponible en: https://www.funlam.edu.co/revistas/index.php/poiesis/article/view/2121

27. Comisión Económica para América Latina y el Caribe. Educación y autonomía económica de las mujeres jóvenes en América Latina y el Caribe CEPAL. [Internet]. 2019 [Citado 30 febrero 2020]. Disponible en: https://www.cepal.org/es/publicaciones/44628-educacion-tecnico-profesional-autonomia-economica-mujeres-jovenes-america-latina

28. Maroto-Navarro G, Ocaña-Riola R, Gil-García E, García-Calvente MM. Análisis multinivel de la producción científica mundial sobre paternidad, desarrollo humano e igualdad de género. GEF Bull Biosci. [Internet]. 2010 [Citado 30 marzo 2018]; 1(1):1-6. Disponible en: https://www-sciencedirect-com.ezproxy.unbosque.edu.co/science/article/ pii/S0213911119301190

29. Salguero-Velázquez A, Córdoba-Basulto D, Sapién-López S. Masculinidad y paternidad: los riesgos en la salud a partir de los aprendizajes de género. Psicol y Salud. [Internet]. 2018 [Citado 20 mayo 2019]28(1):37-44. Disponible en: https://pdfs.semanticscholar.org/f90a/396505940ffc8c991 fa12799e2d79c32a197.pdf

30. Rojas V. El género y las trayectorias hacia la adultez en el Perú: educación, trabajo y maternidad/paternidad. Minist Educ [Internet]. 2017; [Citado 10 enero 2020]1-43. Disponible en: http://repositorio.minedu.gob.pe/handle/MINEDU/5518

31. Jácome-Espinoza GL, Rojas-Jaramillo RR, Toasa-Rocha ES. Maternidad y paternidad de los estudiantes de la Carrera de Enfermería, y su afectación a la formación académica en el periodo 2016-2017. [Tesis en internet]. Quito: Universidad Central de Ecuador; 2017 [Citado 15 febrero 2019]. Disponible en: http://www.dspace.uce.edu.ec/hand- 


\section{$\underline{1 \mathrm{e} / 25000 / 10097}$}

ISSN-PRINT

1794-9831

E-ISSN 2322-7028

Vol. 17 No. 3

Sep - Dic 2020

Cúcuta, Colombia

32. Fernández-Jimeno N. Desafiando la institución de la maternidad: reapropiaciones subversivas de las tecnologías de reproducción asistida (TRA). Rev Iberoam Ciencia, Tecnol y Soc. [Internet]. 2016 [Citado 30 marzo 2018]; 11(31):119-46. Disponible en: https://dialnet.unirioja.es/servlet/articulo?codigo $=5736264$

33. Arango-Gómez LM. La demanda social y la maternidad en mujeres universitarias en la ciudad de Medellín. Integración Académica en Psicología. [Internet]. 2014 [Citado 20 mayo 2019] 2(5):45-53. Disponible en; https://integracion-academica.org/attachments/ article $/ 52 /$ Integraci $\% \mathrm{C3} \% \mathrm{~B} 3 \mathrm{n} \% 20 \mathrm{Acad} \% \mathrm{C} 3 \% \mathrm{~A} 9 \mathrm{mica} \% 20 \mathrm{en} \% 20 \mathrm{Psicolog} \% \mathrm{C} 3 \% \mathrm{~A}-$ Da\%20V2N5\%20op.pdf\#page $=48$

34. Salguero-Velazquez MA, Soriano-Chavero M, Ayaña-Jiménez CD. Estereotipos de género: sexualidad y anticoncepción en jóvenes universitarios de clase media. Investigaciones Feministas [Internet]. 2016 [Citado 30 enero 2019]; 7(1):335-352. Disponible en: https://revistas.ucm.es/index.php/INFE/article/view/51724

35. Barcelo-Tous MI. Un camino hacia la maternidad pospatriarcal. AIBR Rev Antropol Iberoam. [Internet]. 2016 [Citado 30 marzo 2020]; 11(1):131-52. Disponible en: https:// www.redalyc.org/pdf/623/62345164007.pdf

36. Cubillos-Romo JE. Maternidad adolescente, entre la escolarización y el fracaso escolar. Actual Investig en Educ. [Internet]. 2017 [Citado 15 febrero 2019];17(1):1-22. Disponible en: https://www.redalyc.org/pdf/447/Resumenes/Resumen_44758536015 1.pdf

37. Espitia-Cáceres MP, Gómez-Velásquez VM, Minota-Ariza EA, Peña-Cruz JA. Experiencias de maternidad y percepciones de paternidad a través de la autobiografía. [Tesis]. Bogotá: Universidad de la Salle; 2016 [Citado 15 febrero 2019]. Disponible en: https://ciencia.lasalle.edu.co/cgi/viewcontent.cgi?article=1114\&context=trabajo_social

38. Parada-Rico DA, García-Suárez CI. Padres y madres adolescentes en el ejercicio de la crianza. Rev. cienc. cuidad. [Internet]. 2017 [Citado 10 julio 2020]; 14(2):97. Disponible en: https://doi.org/10.22463/17949831.1113

39. Martell N, Ibarra M, Contreras G, Camacho J. La sexualidad en adolescentes desde la teoría de las representaciones sociales. Psicol y Salud [Internet]. 2018 [Citado 15 febrero 2019]; 28(1):15-24. Disponible en: https://www.researchgate.net/publication/323642632_La_sexualidad_en_adolescentes desde_la teoria de las representaciones sociales

40. Nebot L, Díez E, Martín S, Estruga L, Villalbí JR, Pérez G, et al. Efectos de una intervención de consejo anticonceptivo en adolescentes de barrios desfavorecidos con alta proporción de inmigrantes. Gac Sanit. [Internet]. 2016 [Citado 20 mayo 2019]; 30(1):43-6. Disponible en: http://scielo.isciii.es/scielo.php?script=sci arttext\&pi$\underline{\mathrm{d}=\mathrm{S} 0213-91112016000100008}$

41. Instituto Colombiano de Bienestar Familiar - ICBF. Embarazo en adolescentes. Generalidades y percepciones. 2015. Disponible en: https://www.icbf.gov.co/programas-y-estrategias/observatorio-del-bienestar-de-la-ninez/embarazo-en-adolescentes

42. Hernández-Céspedes JD, Velásquez-López RN, Pinzón-Gutiérrez CM. Conocimiento, actitud y práctica en anticoncepción en adolescentes escolarizados en la comuna 1 de Villavicencio. Cienc y Salud Virtual. [Internet]. 2017 [Citado 30 marzo 2020]; 9(1):412. Disponible en: http://revistas.curnvirtual.edu.co/index.php/cienciaysalud/article/ view/775

43. Castañeda-Letelier MF. Ser Estudiantes, Madres y Padres: Una dualidad cotidiana. Repos Académico Chile [Tesis]. Universidad de Chile; 2015 [Citado 15 febrero 2019] Disponible en: http://repositorio.uchile.cl/handle/2250/135041

44. UNESCO. Orientaciones Técnicas Internacionales sobre Educación en Sexualidad. Justificación la Educ en Sex. [Internet]. 2010 [Citado 12 abril 2019]. Disponible en: https:// 
nicaragua.unfpa.org/sites/default/files/pub-pdf/260840s_0.pdf

45. Cárdenas-Molina JE. Sex Education As a Strategy for Inclusion in the All-Round Training of the Teenager. Praxis [Internet]. 2015 [Citado 20 mayo 2019];11(1):103-115. Disponible en: http://revistas.unimagdalena.edu.co/index.php/praxis/article/view/1558

46. Lm L, Bernholc A, Chen M, Ee T. School-based interventions for improving contraceptive use in adolescents. [Internet]. 2016 [Citado 10 enero 2020]. Disponible en: https:// www.cochranelibrary.com/cdsr/doi/10.1002/14651858.CD012249/abstract?cookiesEna$\underline{\text { bled }}$ 